\title{
Proficiency testing for the calibration of masses
}

\author{
Lise HEGRON ${ }^{1, *}$, Boris GEYNET ${ }^{2}$ \\ ${ }^{1,2}$ CT2M, Route de Lançon, Centre des Creusets, 13250 Saint-Chamas, France
}

\begin{abstract}
The CT2M organized in 2018 a european inter-laboratory comparison (ILC) for the calibration of masses. The proficiency testing was particulary intended for the calibration laboratories (accredited or not) but also the testing laboratories carrying out their own calibrations and / or controls of their masses. This circuit took place between April 2018 to October 2018 in five European countries: England, France, Germany, Portugal and Switzerland. The results were processed according to the statistical principle of ISO 13528 [1] and in compliance with the requirements of ISO 17043 [2]. This article presents the organization of this inter-laboratory comparison and the results. The performances of the participants are evaluated and an interpretation of the results is proposed in order to highlight the predominant influence parameters on the mass calibration results (nominal values: $200 \mathrm{mg}, 2 \mathrm{~g}, 20 \mathrm{~g}, 200 \mathrm{~g}$ and $20 \mathrm{~kg}$ ).
\end{abstract}

\section{Introduction}

Accreditation body require accredited laboratories to regularly participate in interlaboratory comparisons (ILC) to prove their ability to perform tests or calibrations. Since 2014 CT2M organized inter-laboratory comparison in various fields to meet that need. In 2018, an inter-laboratory comparison was organized for the calibration of masses. 15 laboratories took part in this round which took place from April 2018 to October 2018. The participants were calibration laboratories (accredited or not) as well as testing laboratories carrying out internal calibrations and / or controls of their masses.

This proficiency testing scheme was organized in accordance with the requirements of ISO 17043 and the results processing and participant performance study were conducted according to the principles of ISO 13258. The results obtained are presented in this paper.

\section{Organisation of the proficiency texting round}

\subsection{Proficiency testing items}

The calibration items consisted in 5 masses:

$\checkmark \quad 4$ masses (OIML class E2) of nominal values: 200mg, $2 \mathrm{~g}, 20 \mathrm{~g}$ and $200 \mathrm{~g}$

$\checkmark \quad 1$ mass (OIML class F1) of nominal value $20 \mathrm{~kg}$.

\footnotetext{
${ }^{*}$ Corresponding author: $\underline{\text { lhegron@ } @ \text { ct } 2 \mathrm{~m} . \mathrm{fr}}$
} 
To ensure the stability of the masses during the ILC round, an accredited reference laboratory, which was not part of the participants, calibrated the masses at the beginning and at the end of the round.

\subsection{Procedure of the proficiency testing}

The preferred calibration method was the reference method of comparing the mass to be calibrated with a standard weight of equivalent nominal value, using a comparator. Each laboratory used its procedure and was free to choose the number of repetitions and the number of calibration cycles (Table 1).

Table 1. Number of repetitions and calibration cycles

\begin{tabular}{|c|c|c|c|c|c|}
\hline \multirow{2}{*}{ Lab } & \multicolumn{5}{|c|}{$\begin{array}{c}\text { Number of repetitions and cycles } \\
\text { (A: standard maa ; B: calibrated mass) }\end{array}$} \\
\cline { 2 - 7 } & $200 \mathrm{mg}$ & $2 \mathrm{~g}$ & $20 \mathrm{~g}$ & $200 \mathrm{~g}$ & $20 \mathrm{~kg}$ \\
\hline 1 & $10 \mathrm{ABAB}$ & $10 \mathrm{ABAB}$ & $10 \mathrm{ABAB}$ & & \\
\hline 2 & $5 \mathrm{ABBA}$ & & $5 \mathrm{ABBA}$ & $5 \mathrm{ABBA}$ & $5 \mathrm{ABBA}$ \\
\hline 3 & $1 \mathrm{ABBA}$ & $1 \mathrm{ABBA}$ & $1 \mathrm{ABBA}$ & $1 \mathrm{ABBA}$ & $2 \mathrm{ABBA}$ \\
\hline 4 & $3 \mathrm{ABBA}$ & $3 \mathrm{ABBA}$ & $3 \mathrm{ABBA}$ & $3 \mathrm{ABBA}$ & $3 \mathrm{ABBA}$ \\
\hline 5 & & $5 \mathrm{AABB}$ & $5 \mathrm{AABB}$ & $5 \mathrm{AABB}$ & \\
\hline 6 & & $2 \mathrm{ABBA}$ & $2 \mathrm{ABBA}$ & $2 \mathrm{ABBA}$ & $2 \mathrm{ABBA}$ \\
\hline 7 & $2 \mathrm{ABBA}$ & $2 \mathrm{ABBA}$ & $2 \mathrm{ABBA}$ & $2 \mathrm{ABBA}$ & $2 \mathrm{ABBA}$ \\
\hline 8 & $2 \mathrm{ABBA}$ & $2 \mathrm{ABBA}$ & $2 \mathrm{ABBA}$ & $2 \mathrm{ABBA}$ & $2 \mathrm{ABBA}$ \\
\hline 9 & $3 \mathrm{ABBA}$ & $3 \mathrm{ABBA}$ & $3 \mathrm{ABBA}$ & $3 \mathrm{ABBA}$ & $3 \mathrm{ABBA}$ \\
\hline 10 & $3 \mathrm{ABBA}$ & $3 \mathrm{ABBA}$ & $3 \mathrm{ABBA}$ & $3 \mathrm{ABBA}$ & $3 \mathrm{ABBA}$ \\
\hline 11 & $5 \mathrm{ABA}$ & $5 \mathrm{ABA}$ & $5 \mathrm{ABA}$ & $5 \mathrm{ABA}$ & $3 \mathrm{ABA}$ \\
\hline 12 & $2 \mathrm{ABBA}$ & $2 \mathrm{ABBA}$ & $2 \mathrm{ABBA}$ & $2 \mathrm{ABBA}$ & $2 \mathrm{ABBA}$ \\
\hline 13 & $2 \mathrm{ABABA}$ & $2 \mathrm{ABABA}$ & $2 \mathrm{ABABA}$ & $2 \mathrm{ABABA}$ & $2 \mathrm{ABA}$ \\
\hline 14 & & & $10 \mathrm{ABBA}$ & $10 \mathrm{ABBA}$ & \\
\hline 15 & $4 \mathrm{ABBA}$ & $4 \mathrm{ABBA}$ & $4 \mathrm{ABBA}$ & $4 \mathrm{ABBA}$ & \\
\hline
\end{tabular}

The participants used their own means of calibration, namely:

$\checkmark$ Standard masses of nominal values equivalent to the masses to be calibrated,

$\checkmark \quad$ A scale or a comparator.

The characteristics of the standard masses, of the scale / comparator and of environmental conditions had been indicated by the participants.

The participants had to determine the conventional mass of each calibrated mass. In addition, the following information could be mentioned :

$\checkmark$ The expanded calibration uncertainty $(\mathrm{k}=2)$,

$\checkmark$ Influence factors considering for the uncertainty calculation,

$\checkmark$ Environmental conditions during calibration. 


\section{Method for data analysis}

\subsection{Hypothesis for data analysis}

The purpose of the proficiency testing is to conduct an assessment of laboratory performance by comparing their results with each other and against a reference value. Assumptions were considered for the data analysis to make consistent conclusions on the results.

In accordance with the reference standards [1] [3] [4], the assumption of a normal distribution of the data series has been made. This hypothesis has been verified for for all results using the following two methods:

$\checkmark$ Graphical Method (normal probability plot)

$\checkmark \quad$ Statistical method (Shapiro-Wilk)

The Grubbs test was performed on all the conventionnal masses determined by each of the participant. The purpose of this test is to identify a laboratory with an incoherent result compared to other participants. The test involves calculating the Grubbs parameter $(\mathrm{G})$ and comparing it to the critical Grubbs values in the Table 5 of ISO 5725-2 [3].

Only one outlier was highlighted by the Grubbs test. It was the conventional mass of the weight of $2 \mathrm{~g}$ obtained by the laboratory No.13 whose value was abnormally low (Fig. 3a).

\subsection{Assigned values and standard deviations}

\subsubsection{Reference value and uncertainty}

The reference values of this proficiency testing were obtained by a reference laboratory that is accredited according to ISO/IEC 17025. It calibrated the masses at the beginning and at the end of the ILC round. The reference value $\mathrm{x}_{\mathrm{ref}}$ is the average of both conventional masses. Its associated uncertainty $U_{\text {ref }}$ takes into account the uncertainty of the reference laboratory as well as the possible drift of the masses between the beginning and the end of the round.

Table 2. Reference values and uncertainties

\begin{tabular}{|c|c|c|}
\hline \multirow{2}{*}{ Mass } & \multicolumn{2}{|c|}{ Reference values } \\
\cline { 2 - 3 } & $\mathbf{x}_{\text {ref }}(\mathbf{g})$ & $\mathbf{U}_{\text {ref }}(\mathbf{g}) \mathbf{k}=\mathbf{2}$ \\
\hline $200 \mathrm{mg}$ & 0,2000038 & 0,0000062 \\
\hline $2 \mathrm{~g}$ & 1,999987 & 0,000013 \\
\hline $20 \mathrm{~g}$ & 19,999937 & 0,000026 \\
\hline $200 \mathrm{~g}$ & 199,99977 & 0,00011 \\
\hline $20 \mathrm{~kg}$ & 20000,016 & 0,031 \\
\hline
\end{tabular}

The table 2 lists the reference values and their associated uncertainties.

\subsubsection{Robust mean and robust standard deviation}

The robust mean $\mathrm{x}^{*}$ and the robust standard deviation $\mathrm{S}^{*}$ are determined using the algorithm A defined in ISO 13528. The robust average and standard deviation are used to 
evaluate the Z-score of each participant. The Table 3 shows the parameters obtained for all the tests, ie.:

$-\mathrm{X}^{*}$ : robust average

- $\mathrm{S}^{*}$ : robust standard deviation

- $\mathrm{U}_{\mathrm{x}} *$ : uncertainty on the robust average

Table 3. Robust mean and standard deviation

\begin{tabular}{|c|c|c|c|c|}
\hline \multirow{2}{*}{ Mass } & \multirow{2}{*}{$\begin{array}{c}\text { Number } \\
\text { of lab. }\end{array}$} & \multicolumn{3}{|c|}{ Robust mean and standard deviation } \\
\cline { 3 - 5 } & 12 & 0,2000020 & 0,0000092 & 0,0000067 \\
\hline $200 \mathrm{mg}$ & $\mathbf{( g )}$ & $\mathbf{S}^{*}(\mathbf{g})$ & $\mathbf{U}_{\mathbf{*}^{*}}(\mathbf{g}) \mathbf{k}=\mathbf{2}$ \\
\hline $2 \mathrm{~g}$ & 13 & 1,9999930 & 0,0000061 & 0,0000043 \\
\hline $20 \mathrm{~g}$ & 15 & 19,9999440 & 0,0000130 & 0,0000085 \\
\hline $200 \mathrm{~g}$ & 14 & 199,999798 & 0,000092 & 0,000063 \\
\hline $20 \mathrm{~kg}$ & 11 & 20000,016 & 0,014 & 0,011 \\
\hline
\end{tabular}

\subsubsection{Comparison between the robust averages and the reference values}

When organizing an inter-laboratory comparison, it is important to ensure that the robust averages of the participants results are not significantly different from the reference values. The graphs below show a good correspondence between the robust means and the reference values for each of the calibrated masses.

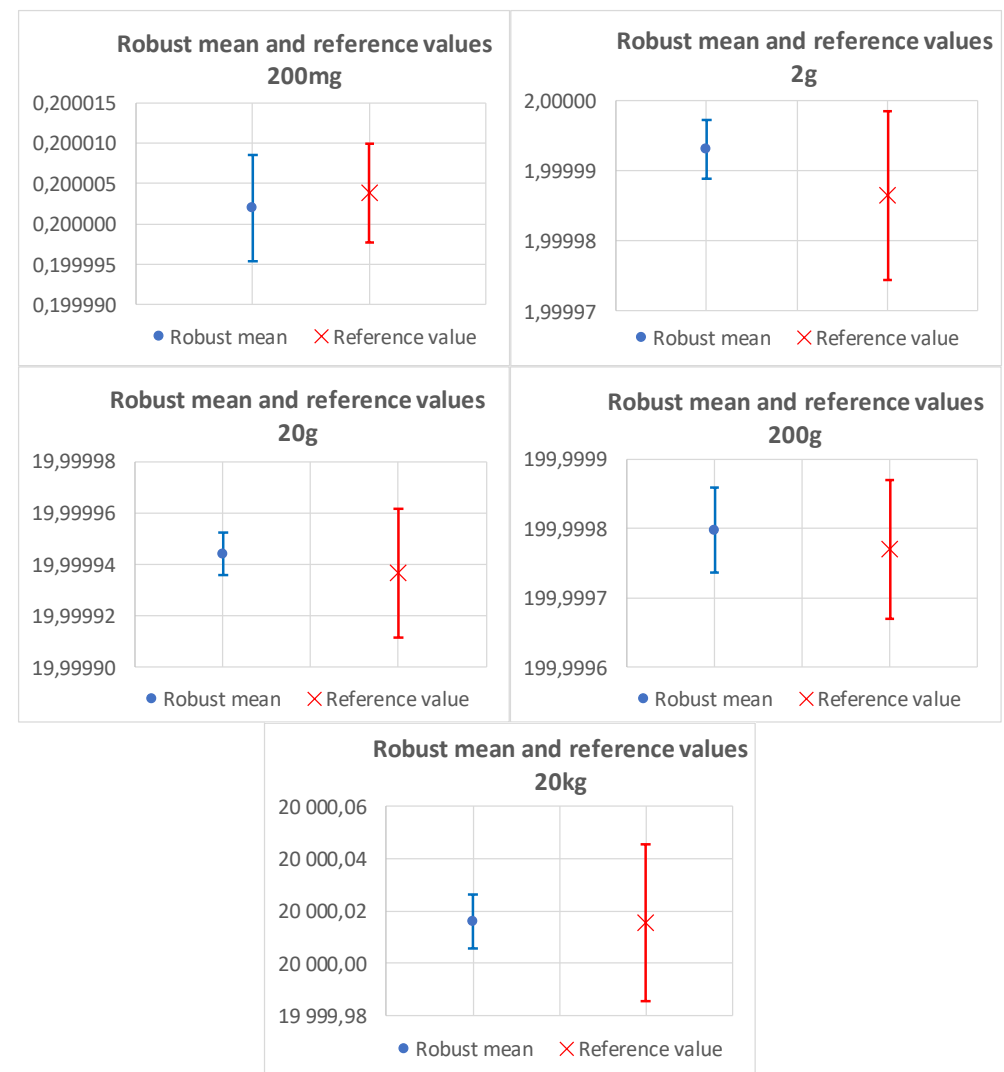

Fig. 1. Comparison between the robust means and the reference values 
The number $E n$ highlights the difference between the robust average with its uncertainty and the reference value with its uncertainty (Table 4). The number En between both the results are in the range $[-1 ; 1]$ for all the calibrated masses. It is therefore possible to conclude that there is no significant difference between the reference values (obtained by the reference laboratory) and the robust averages (participants results).

Table 4. Number En

\begin{tabular}{|c|c|c|}
\hline Mass & Number of lab. & En \\
\hline $200 \mathrm{mg}$ & 12 & $-0,20$ \\
\hline $2 \mathrm{~g}$ & 13 & 0,51 \\
\hline $20 \mathrm{~g}$ & 15 & 0,28 \\
\hline $200 \mathrm{~g}$ & 14 & 0,24 \\
\hline $20 \mathrm{~kg}$ & 11 & 0,01 \\
\hline
\end{tabular}

\section{Participant results}

The results for the 5 masses are presented in the following graphs. They show the conventional masses and their uncertainties associated with $\mathrm{k}=2$ (error bars). For each calibration point, a histogram also shows the frequency of the results (number of laboratories) according to the class of values.

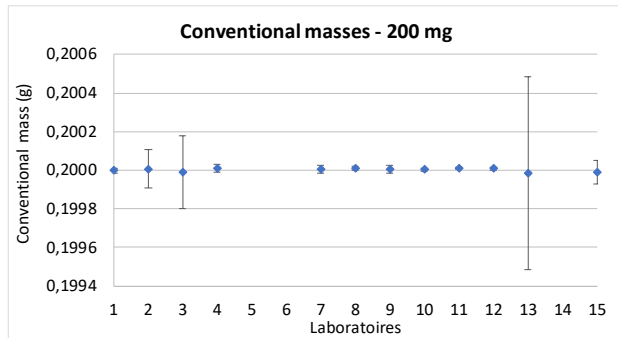

Fig. 2a. Conventional masses and their uncertainties for $200 \mathrm{mg}$

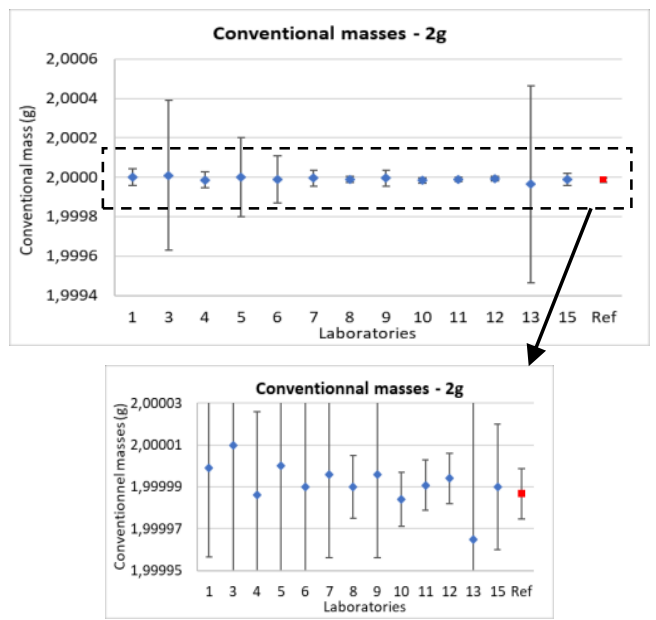

Fig. 3a. Conventional masses and their uncertainties for $2 \mathrm{~g}$

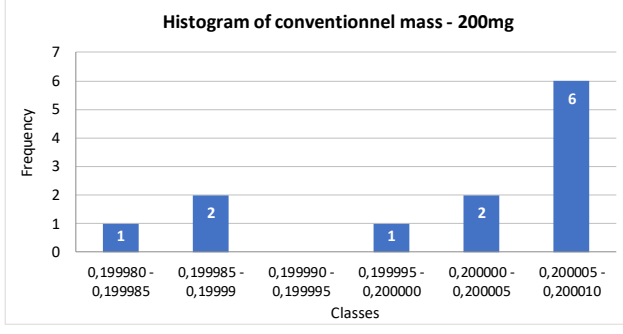

Fig. 2b. Histogram of conventional mass for $200 \mathrm{mg}$

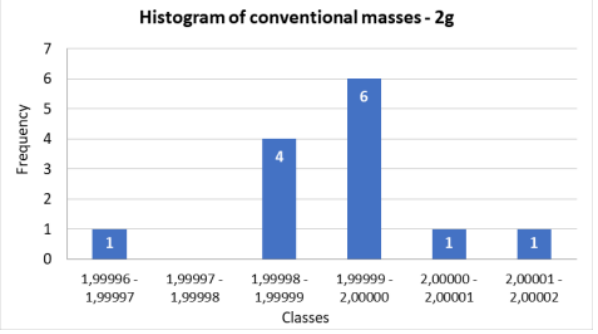

Fig. 3b. Histogram of conventional masses for $2 \mathrm{~g}$ 


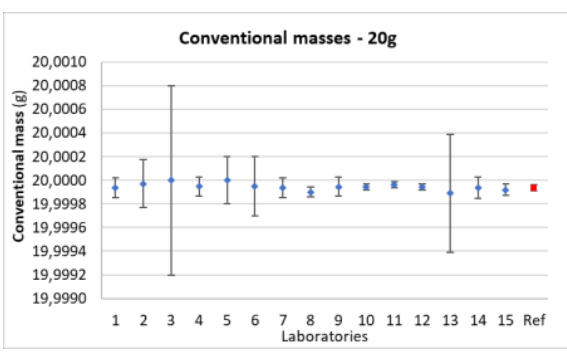

Fig. 4a. Conventional masses and their uncertainties for $20 \mathrm{~g}$

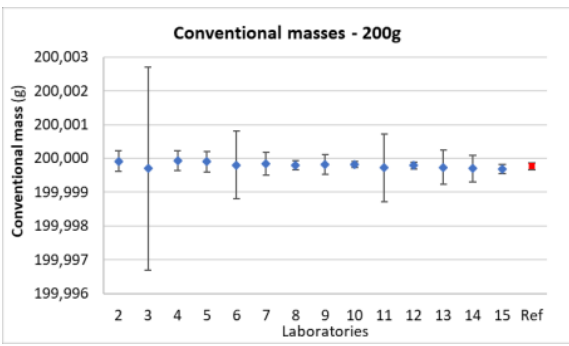

Fig. 5a. Conventional masses and their uncertainties for $200 \mathrm{~g}$

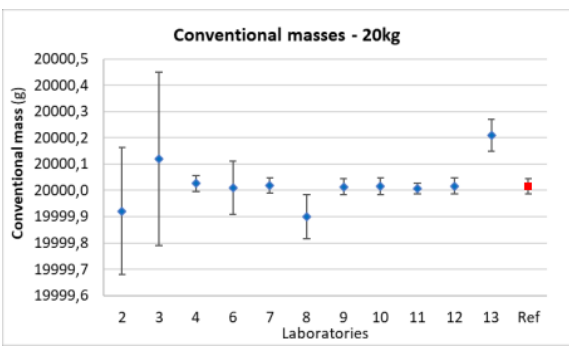

Fig. 6a. Conventional masses and their uncertainties for $20 \mathrm{~kg}$

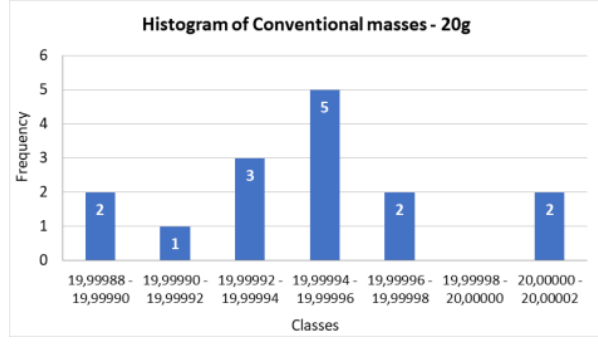

Fig. 4b. Histogram of conventional masses for $20 \mathrm{~g}$

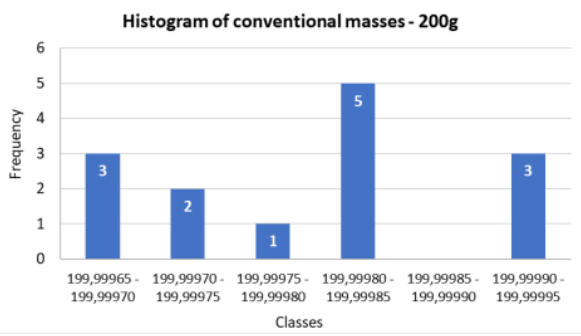

Fig. 5b. Histogram of conventional masses for $200 \mathrm{~g}$

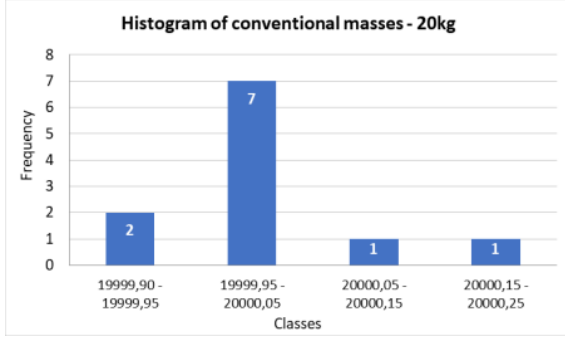

Fig. 6b. Histogram of conventional masses for $20 \mathrm{~kg}$

\section{Participant performance}

The laboratories performance is determined by the Z-score that is a standardized measure of the bias. This performance score is calculated using the following formula:

$$
Z=\frac{\left(x_{l a b}-x^{*}\right)}{S^{*}}
$$

The reference value $x^{*}$ is the robust average of the participants results, the value $\mathrm{x}_{\mathrm{lab}}$ is the value obtained by the laboratory and the parameter $S^{*}$ is the robust standard deviation of the participants results.

For each participant, the $\mathrm{Z}$-scores were calculated for each calibrated mass (Fig. 7). The Zscores between -2 and -3 or 2 and 3 correspond to isolated result. The Z-scores less than -3 or greater than 3 correspond to discordant result. 


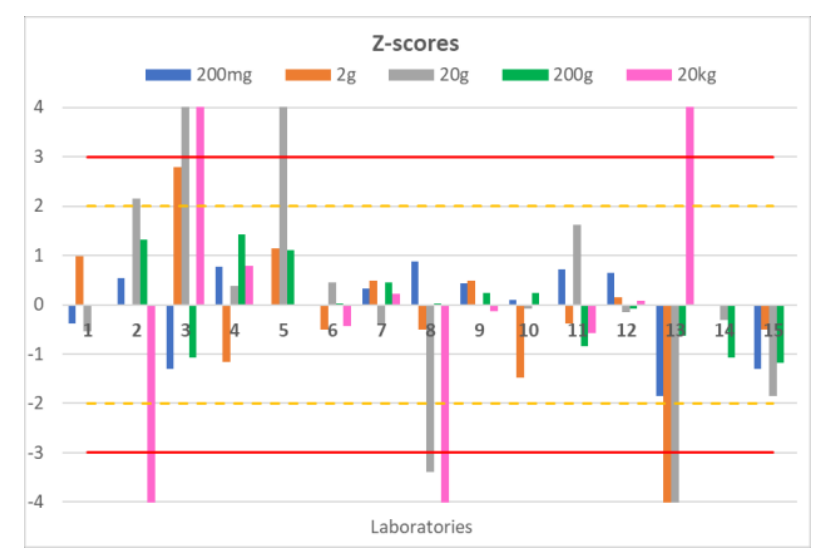

Fig. 7. Z-scores of each participant for all the calibrated masses

If a laboratory obtains a positive (or negative) Z-score for all the calibrated masses, this highlights an overall bias (systematic error) on the calibration process compared to the average of the participants. This bias is all the more so high as the values of Z-scores is far from 0 .

An interpretation of the results in relation to the reference value was also performed using the number $E n$. It is a parameter that lead to evaluate wthe difference between 2 values. The values are compared taking into account their associated expanded uncertainties. The results of the participants are therefore compared to the reference value. The number En is calculated using the following formula:

$$
E n=\frac{x_{l a b}-x_{r e f}}{\sqrt{{U_{l a b}{ }^{2}+U_{r e f}^{2}}^{2}}}
$$

- $\mathrm{X}_{\mathrm{ref}}$ is the reference value (reference laboratory),

- $\mathrm{X}_{\mathrm{lab}}$ is the laboratory value,

- $\mathrm{U}_{\text {ref }}$ is the uncertainty $(\mathrm{k}=2)$ on the reference value,

- $\mathrm{U}_{\text {lab }}$ is the uncertainty $(\mathrm{k}=2)$ on the laboratory value.

The Figure 8 shows the results of all the numbers $E n$ for the different calibrated masses. If a laboratory obtains a positive (or negative) number $E n$ on all the calibrated masses, this highlights an overall bias (systematic error) on the calibration process compared to the reference value. This bias is all the more so important as the number $E n$ is far from 0 . 


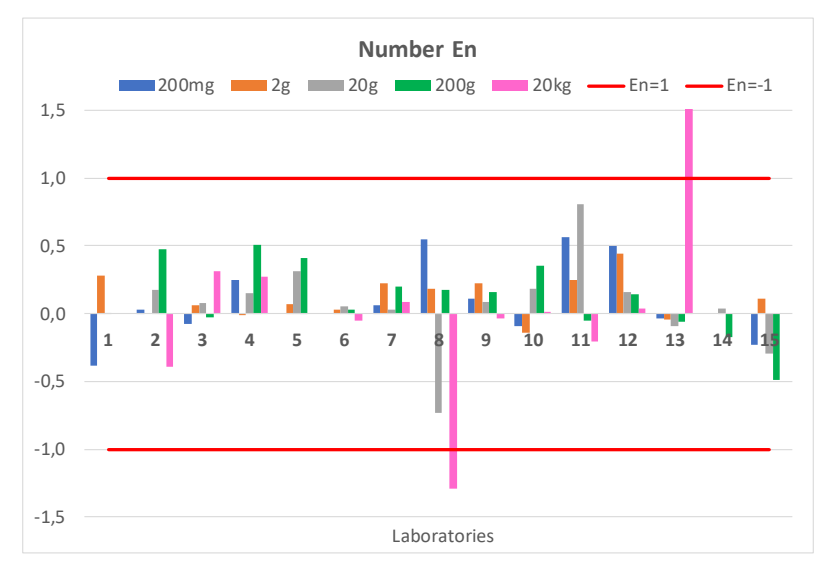

Fig. 8. Numbers $E n$ for all the masses

The interpretation of the number En must be done with caution. Indeed some laboratories have significant uncertainties, which leads to a correct standardized deviation (less than 1 or more than -1) despite significant bias compared to the reference value (laboratory No.3 for example).

\section{Conclusions}

This inter-laboratory comparison bringing together a sufficient number of laboratories made it possible to highlight several conclusions.

The results of the participants were exploited and performance criteria were provided to participants so that they could either validate their calibration method as accreditation bodies, or improve it by triggering actions to correct a possible bias.

It should be noted that several accredited laboratories participated in this inter-laboratory comparison have results that are significantly different from the assigned values. Moreover, no correlation can be make with the country of the laboratories.

\section{References}

1. ISO 13528 October 2015: Statistical methods for use in proficiency testing by interlaboratory comparisons

2. EN ISO/CEI 17043 April 2010: Conformity assessment - General requirements for proficiency testing

3. ISO 5725-2 December 1994 : Accuracy (trueness and precision) of measurement methods and results - Part 2: Basic method for the determination of repeatability and reproducibility of a standard measurement method 